\title{
Household Food Insecurity and Its Association with Self-reported Infectious and Parasitic Diseases Among Household Mothers in Southeast of Iran
}

\author{
Zinat Mortazavi, ${ }^{1,}$ Ahmad Reza Dorosty, ${ }^{1}$ Mohammad Reza Eshraghian, ${ }^{2}$ Mohtasham Ghaffari, ${ }^{3}$ and \\ Alireza Ansari-Moghaddam ${ }^{4}$ \\ ${ }^{1}$ Department of Community Nutrition, School of Nutritional Sciences and Dietetics, Tehran University of Medical Sciences, Tehran, Iran \\ ${ }^{2}$ Epidemiology and Biostatistics Department, School of Health, Tehran University of Medical Sciences, Tehran, Iran \\ ${ }^{3}$ Environmental and Occupational Hazards Control Research Center, School of Public Health, Shahid Beheshti University of Medical Sciences, Tehran, Iran \\ ${ }^{4}$ Health Promotion Research Center, Zahedan University of Medical Sciences, Zahedan, Iran \\ "Corresponding author: Zinat Mortazavi, PhD student of Nutrition, Department of Community Nutrition, School of Nutritional Sciences and Dietetics, Tehran University of \\ Medical Sciences, Tehran, Iran. Tel: +98-9151414868, E-mail: zimoiran@yahoo.com
}

Received 2016 July 05; Revised 2016 October 17; Accepted 2016 November 04.

\begin{abstract}
Background: Nowadays, more than 1 billion people suffer from food insecurity worldwide. Food insecurity is recognized as an important determinant of health, and both food insecurity and diseases are public health concerns. This study aimed at determining the association between food insecurity and self-reported history of infectious and parasitic diseases among household mothers in Zahedan, southeast of Iran.

Methods: This cross-sectional study was conducted on 2160 households in Zahedan. Food insecurity of the households was assessed through USDA18-item questionnaire. Demographic data and questions about history of infectious and parasitic diseases in mothers were collected through interviewing the mothers. The data were analyzed using chi-square test and logistic regression model.

Results: Of the household mothers, 58.8\% experienced food insecurity, $11.5 \%$ reported history of infectious diseases, and 1.1\% experienced parasitic diseases in the last 3 months. After adjusting for the selected variables, a positive association was detected between food insecurity and history of infectious (OR, 2.29; 95\% CI, 1.66 - 3.18) and parasitic diseases (OR, 3.86; 95\% CI, 1.07 - 13.93) in mothers. Conclusions: Food security seems a controllable environmental factor that may cause some positive results in the fight against diseases. On the other hand, preventing and controlling infectious and parasitic diseases may in turn result in reduction of food insecurity.
\end{abstract}

Keywords: Food Insecurity, Infectious Diseases, Parasitic Diseases, Self-Reported History

\section{Background}

Food insecurity is defined as follows: Uncertain or limited access to adequate nutritious and safe foods or uncertain or limited ability to acquire acceptable foods in socially acceptable ways (1-6). Food insecurity is common in developing countries and is associated to the physical wellbeing of the households (7). Today, more than 1 billion people are very poor and suffer from food insecurity worldwide (8). The world's population is predicted to grow to approximately 9.2 billion by 2050 . Food insecurity is an international concern because it weakens social and economic development, causes environmental demolition, raises the spread of diseases, and eventually, threatens global peace (9). Disease and malnutrition have an interaction in an important feedback loop, affecting food and nutrition security (10). Food insecurity can be both a by-product of and a precursor to poverty and disease. Individuals who are food insecure may eat cheap food, skip meals, and experience stress. Food security can help improve patients' health in the long term and may reduce their need for clinical care (11). There are some biological mechanisms in which food insecurity and poor nutrition lead to poor health (12). Infectious agents and parasites can interfere in the equilibrium between the external and internal environment, determining major or minor actuation of factors related to the nutritional state. Host nutritional status has an important role in the susceptibility to viral infections, bacteria, and parasites. Infection accelerates the appearance of signs and symptoms of nutrition deficiencies in the undernourished individuals and can exacerbate the evolution of the infection process; they both interact synergistically and are a public health problem, mainly in areas of poor basic sanitation; poverty and ignorance also influence eating habits (13). Infections can lead to loss of appetite, decreased nutrient utilization, and efficiency of food, and increased energy requirements (14). Parasites are organisms 
that feed from other living organisms known as hosts. Parasites may be transmitted from host to host through consumption of contaminated water and food, or by anything that has touched the feces of the animal or the infected person (15). Intestinal parasites may be associated with anemia, a decrease in food intake, endogenous nutrient loss, and malabsorption. Although it is acknowledged that parasites may lead to malnutrition, the extent to that malnutrition itself causes increased parasite contamination (16).

Food insecurity is related to a range of poor health implications in adults, adolescents, and children. It also affects both physical and psychosocial health outcomes and leads to overall poorer health among food insecure households (17).

The prevalence of food insecurity in various regions of the world is different. In a systematic review and metaanalysis conducted in Iran, the prevalence of food insecurity in households was $49 \%$ (18). In Iran, no study has investigated the association between food insecurity and infectious and parasitic diseases. However, in 2 studies conducted in Iran, the prevalence of food insecurity in the patients with upper gastrointestinal cancers in Tehran, and in those with Type 2 diabetes in Shiraz was reported to be $69.17 \%$ and $66.7 \%$, respectively $(19,20)$.

In Alaska, a high prevalence of public health influence of food insecurity in adults with a range of chronic diseases was found (21). In the United States and Canada, significant associations were found between food insecurity and poor or fair self-rated health and multiple chronic conditions. In Canada, the severity of household food insecurity was associated with poorer self-rated health and chronic conditions. The prevalence of most chronic conditions rose with worsening household food insecurity $(22,23)$.

Food insecurity is associated with a number of socioeconomic factors $(21,24)$. Food insecurity is the converse state and has important consequences for the nutrition and health of the individuals.

Women require special attention in discussions of food insecurity and its effect on nutrition, health, and behavior. Considering the traditional role of women as caregivers and preparers of food for the family, more support and attention should paid to them as a special group to evaluate the effect, consequences, and field for intervention in food insecurity (25).

This study aimed at determining the association between food insecurity and self-reported history of infectious and parasitic diseases among mothers in Zahedan, southeast of Iran.

\section{Methods}

\subsection{Sampling Method}

In the present cross-sectional study, 2160 households in Zahedan were investigated. The city of Zahedan was divided into 5 geographical areas (North, South, East, West, and Center). Two health care centers were randomly selected from each geographical area. Each Center covered a number of household blocks; the blocks were numbered systematically, and then, considering the sample size required, blocks were randomly selected to be included in the study.

\subsection{Sociodemographic Data}

History of infectious (acute/chronic) and parasitic diseases among mothers was assessed by asking them about the history of infectious and parasitic diseases in the last 3 months. Most mothers with positive response to these questions were visited by a physician or referred for laboratory tests to confirm their disease.

Sociodemographic data including ethnicity, employment status, age, and education level of mothers were collected through a general questionnaire in a face to face interview.

\subsection{Household Food Insecurity}

Food insecurity of the household was assessed through USDA 18-item food security questionnaire (26); this questionnaire was validated in some other studies conducted in Iran $(27,28)$. This questionnaire, which evaluated food security status of the households in the last 12 months, was completed through interviews with the mother or the person responsible for preparing food for the family; the maximum score of this questionnaire is 18 . To determine food security of the households, based on the obtained score, the households were classified as follow: scores 0 to 2: food secure; 3 to 7: food insecure without hunger; 8 to 12: food insecure with moderate hunger; and 13 to 18 : food insecure with severe hunger $(24,27)$.

\subsection{Data Analysis}

Data were analyzed using SPSS 20 (SPSS Inc. Chicago, IL, USA). The prevalence of food insecurity of the households and the self-reported history of infectious and parasitic diseases in mothers was determined. The association between household food insecurity with self-reported history of infectious and parasitic diseases in mothers as well as sociodemographic variables was assessed. Descriptive statistical methods and chi-square test were used. Finally, variables associated with food insecurity and self-reported history of infectious and parasitic diseases along with food 
insecurity variable in mothers were entered into logistic regression model. Significance level was set at $<0.05$.

Because various factors may influence the status of household food security and some diseases including infectious and parasitic diseases and may also have a potential confounding effect on the relationship between food insecurity and the risk of these diseases, some of these factors such as ethnicity, employment status, age, and education level of the mothers were included in all models.

\section{Results and Discussion}

In the present study, food insecurity in the investigated households was $58.8 \%$, food insecurity without hunger was $31.7 \%$, food insecurity with moderate hunger found to be $19.7 \%$, and food insecurity with severe hunger was $7.4 \%$. The prevalence of self-reported history of infectious and parasitic diseases in mothers was $11.5 \%$ and $1.1 \%$, respectively.

For statistical analyses, the different categories of food insecurity were integrated into 2 categories and then household food security status as food secure and food insecure was determined.

Due to the limited number of other ethnic groups present in the study, they were integrated into Fars ethnicity.

Statistical analyses were performed in several stages. First, the relationship between household food insecurity and history of infectious and parasitic diseases in mothers with mentioned variables were measured with chi-square test (Table 1).

Then, the association between household food insecurity with self-reported history of infectious and parasitic diseases in mothers was determined.

Based on the results of the chi-square test, there was a statistically significant association between household food insecurity and self-reported history of infectious diseases in mothers with ethnicity, employment status, and education level of mothers $(\mathrm{P}<0.05)$, but the association with age of the mothers was not significant.

Also, a statistically significant association was obtained between self-reported history of parasitic disease in mothers and their education level, but the association between self-reported history of parasitic disease in mothers and their ethnicity, employment status, and age was not significant (Table 1 ).

Baluch ethnics had higher (74.5\%) food insecurity than the Fars (51.8\%), and also self-reported history of infectious diseases in mothers of Baluch households (16.1\% vs. 9.5\%) was higher (Table 1).

The highest prevalence of food insecurity (85.5\%) and self-reported history of infectious diseases in mothers (17.8\%) was observed in households in which the mother was illiterate. The highest prevalence of self-reported history of parasitic diseases was observed in mothers with elementary education (2.4\%) and illiterate mothers (2.0\%).

There was higher household food insecurity (63.7\% vs. $31.6 \%)$ and self-reported history of infectious diseases in those mothers (12.3\% vs. $7.5 \%$ ) who were housewives (Table 1).

The assessment of association between household's food insecurity and self-reported history of infectious and parasitic diseases in mothers, using chi-square test, revealed that this relationship was significant $(\mathrm{P}<0.05)$. Mothers in food insecure households had higher selfreported history of infectious (76.7\%) and parasitic diseases (87.0\%) compared to mothers of food secure households.

The comorbidity of food insecurity with history of infectious and parasitic diseases in mothers was conducted by means of logistic regression model, and crude OR was determined (Table 2).

Ultimately, variables associated with food insecurity and self-reported history of infectious and parasitic diseases in mothers along with food insecurity variable were entered into the logistic regression model. Significance level was set at $<0.05$.

In the logistic regression model, food insecurity was positively and significantly associated with higher odds of self-reported history of infectious and parasitic diseases in mothers.

In the unadjusted model, food insecurity was associated with increased odds of reporting history of infectious (OR, 2.54; 95\% CI, 1.87-3.46) and parasitic (OR, 4.74; 95\% CI, 1.40 - 15.99) diseases in mothers (Table 2). This association remained after adjusting for the potentially confounding effects of ethnicity, employment status, age, and education level of the mothers. Adjusted OR for history of infectious diseases was 2.29; 95\% CI, 1.66 - 3.18 (Table 3), and adjusted OR for history of parasitic diseases was 3.86; 95\% CI, 1.07 13.93 (Table 4).

Food security, described by availability of and access to adequate food, is an important social determinant of health. Therefore, food security is a highly important social determinant with a potential for wide public health impact (29).

In the present study, $58.8 \%$ of the households experienced food insecurity, $11.5 \%$ of the mothers reported history of infectious diseases, and $1.1 \%$ had a history of parasitic diseases in the last 3 months. Mothers who reported a positive history of infectious and parasitic diseases were more likely to be food insecure compared to those mothers who did not have a history of infectious and parasitic diseases.

In Iran, based on a systematic review, the prevalence of food insecurity in households is $49.0 \%$ (18). In a study 
Table 1. Association Between Household Food Insecurity and Self-Reported History of Infectious and Parasitic Diseases in Mothers with Selected Variables ${ }^{\mathrm{a}}$

\begin{tabular}{|c|c|c|c|c|c|c|c|c|c|c|c|}
\hline \multirow{2}{*}{\multicolumn{2}{|c|}{ Variable }} & \multicolumn{2}{|c|}{ Food Security Status } & \multirow{2}{*}{$\begin{array}{c}\chi^{2} \mathbf{p} \\
\text { Value } \\
\end{array}$} & \multicolumn{2}{|c|}{ Self-Reported History of Infectious Diseases } & \multirow{2}{*}{$\begin{array}{c}\chi^{2} \mathbf{P} \\
\text { Value } \\
\end{array}$} & \multicolumn{2}{|c|}{ Self-Reported History of Parasitic Diseases } & \multirow{2}{*}{$\begin{array}{r}\chi^{2} \mathbf{p} \\
\text { Value }\end{array}$} & \multirow[t]{2}{*}{ Total } \\
\hline & & $\begin{array}{c}\text { Food } \\
\text { secure }\end{array}$ & $\begin{array}{c}\text { Food } \\
\text { insecure }\end{array}$ & & Yes & No & & Yes & No & & \\
\hline Materı & li education & & & $<0.001$ & & & 0.008 & & & 0.013 & \\
\hline & Illiterate & $22(14.5)$ & $130(85.5)$ & & $27(17.8)$ & $125(82.2)$ & & $3(2.0)$ & $149(98.0)$ & & $152(100)$ \\
\hline & $\begin{array}{l}\text { Elemen- } \\
\text { tary }\end{array}$ & $110(24.0)$ & $348(76.0)$ & & $51(11.1)$ & $407(88.9)$ & & $11(2.4)$ & $447(97.6)$ & & $458(100)$ \\
\hline & $\begin{array}{l}\text { Secondary } \\
\text { school }\end{array}$ & $138(35.7)$ & $249(64.3)$ & & $51(13.2)$ & $336(86.8)$ & & $3(0.8)$ & $384(99.2)$ & & $387(100)$ \\
\hline & $\begin{array}{l}\text { High } \\
\text { school and } \\
\text { diploma }\end{array}$ & $286(42.4)$ & $388(57.6)$ & & $82(12.2)$ & $592(87.8)$ & & $3(0.4)$ & $671(99.6)$ & & $674(100)$ \\
\hline & $\begin{array}{l}\text { University } \\
\text { education }\end{array}$ & $335(68.5)$ & $154(31.5)$ & & $38(7.8)$ & $451(92.2)$ & & $3(0.6)$ & $486(99.4)$ & & $489(100)$ \\
\hline $\begin{array}{l}\text { Mothe } \\
\text { emplo }\end{array}$ & $\begin{array}{l}\text { s } \\
\text { ment status }\end{array}$ & & & $<0.001$ & & & 0.013 & & & 0.787 & \\
\hline & $\begin{array}{l}\text { House- } \\
\text { keeper }\end{array}$ & $664(36.3)$ & $1164(63.7)$ & & $224(12.3)$ & $1604(87.7)$ & & $19(1.0)$ & $1809(99.0)$ & & $1828(100)$ \\
\hline & Employed & $227(68.4)$ & $105(31.6)$ & & $25(7.5)$ & $307(92.5)$ & & $4(1.2)$ & $328(98.8)$ & & $332(100)$ \\
\hline Materr & lage, $y$ & & & 0.467 & & & 0.095 & & & 0.975 & \\
\hline & $\leq 26$ & $289(39.6)$ & $441(60.4)$ & & $97(13.3)$ & $633(86.7)$ & & $8(1.1)$ & $722(98.9)$ & & $730(100)$ \\
\hline & $27 \cdot 35$ & $332(41.5)$ & $468(58.5)$ & & $92(11.5)$ & $708(88.5)$ & & $8(1.0)$ & $792(99.0)$ & & $800(100)$ \\
\hline & $\geq 35$ & $270(42.9)$ & $360(57.1)$ & & $60(9.5)$ & $570(90.5)$ & & $7(1.1)$ & $623(98.9)$ & & $630(100)$ \\
\hline Ethnic & & & & $<0.001$ & & & $<0.001$ & & & 0.071 & \\
\hline & $\begin{array}{l}\text { Fars (and } \\
\text { other } \\
\text { ethnic) }\end{array}$ & $723(48.2)$ & $777(51.8)$ & & $143(9.5)$ & $1357(90.5)$ & & $12(0.8)$ & $1488(99.2)$ & & $1500(100)$ \\
\hline & Baluch & $168(25.5)$ & $492(74.5)$ & & $106(16.1)$ & $554(83.9)$ & & $11(1.7)$ & 649 (98.3) & & $660(100)$ \\
\hline Total & & $891(41.2)$ & $1269(58.8)$ & & $249(11.5)$ & $1911(88.5)$ & & $23(1.1)$ & $2137(98.9)$ & & $2160(100)$ \\
\hline
\end{tabular}

a Values are expressed as No.(\%)

Table 2. Crude OR for the Association Between Household Food Insecurity with Self-Reported History of Infectious And Parasitic Diseases in Mothers of Households ( $=2160$ )

\begin{tabular}{|c|c|c|c|c|}
\hline \multirow[t]{2}{*}{ Variable } & \multirow[t]{2}{*}{ No. } & \multicolumn{2}{|c|}{ Food Insecurity $^{\mathrm{a}}$} & \multirow[t]{2}{*}{ P Value } \\
\hline & & No. $(\%)$ & Crude OR $(95 \%$ CI $)$ & \\
\hline \multicolumn{5}{|c|}{ Self-reported history of Infectious diseases (acute/chronic) } \\
\hline Yes & 249 & $191(76.7)$ & $2.54(1.87-3.46)$ & $<0.001$ \\
\hline No & 1911 & $1078(56.4)$ & 1.00 & \\
\hline \multicolumn{5}{|c|}{ Self-reported history of Parasitic diseases } \\
\hline Yes & 23 & $20(87.0)$ & $4.74(1.40-15.99)$ & 0.012 \\
\hline No & 2137 & $1249(58.4)$ & 1.00 & \\
\hline
\end{tabular}

Abbreviations: OR, Odds Ratio; CI, Confidence Interval.

${ }^{\mathrm{a}}$ Reference category is: food secure.

conducted on the patients with upper gastrointestinal cancers in Tehran, having children less than 18 years, and low economic levels were independently and directly associated with food insecurity (19). In diabetic patients studied in Shiraz, food insecurity was significantly associated with economic status, education level, income, having a child under 18, family size, and number of children; however, there was not any significant association between food insecurity and age, occupation, marital status, family history of diabetes, high blood pressure, and heart disease (20).

In the U.S. NHANES, a study in Canadian population indicated that household food insecurity is associated with an increased nutritional vulnerability, poor health, and multiple chronic conditions among adults. Thus, regardless of household sociodemographic characteristics, most chronic conditions increased the odds of household food insecurity. The odds of household food insecurity were $1.43,1.86$, and 3.44 for adults with 1,2 , and, 3 or more chronic 
Table 3. Adjusted Odds Ratio for the Association Between Household Food Insecurity and Self-Reported History of Infectious Diseases in Mothers of Households ( $\mathrm{N}=$ $2160)^{\mathrm{a}}$

\begin{tabular}{|c|c|c|}
\hline \multirow[t]{2}{*}{ Variable } & \multicolumn{2}{|c|}{ Food Insecurity } \\
\hline & Adjusted $^{\mathrm{a}}$ OR $(95 \% \mathrm{CI})$ & Pvalue \\
\hline \multicolumn{3}{|l|}{$\begin{array}{l}\text { Self-reported history of infectious } \\
\text { diseases }\end{array}$} \\
\hline Yes & $2.29(1.66-3.18)$ & $<0.001$ \\
\hline No & 1.00 & \\
\hline \multicolumn{3}{|l|}{ Maternal education } \\
\hline Illiterate & $8.49(4.93-14.64)$ & $<0.001$ \\
\hline Elementary & $4.93(3.50-6.97)$ & $<0.001$ \\
\hline Secondary school & $2.85(2.06-3.94)$ & $<0.001$ \\
\hline High school and diploma & $2.31(1.75-3.05)$ & $<0.001$ \\
\hline University education & 1.00 & \\
\hline \multicolumn{3}{|l|}{ Mother's employment Status } \\
\hline Housekeeper & $1.57(1.15-2.13)$ & 0.004 \\
\hline Employed & 1.00 & \\
\hline \multicolumn{3}{|l|}{ Maternal age, $y$} \\
\hline$\leq 26$ & $1.08(0.84-1.41)$ & 0.515 \\
\hline $27-35$ & $1.30(1.02-1.66)$ & 0.032 \\
\hline$\geq 35$ & 1.00 & \\
\hline \multicolumn{3}{|l|}{ Ethnicity } \\
\hline Fars (and other ethnic) & $0.67(0.53-0.86)$ & 0.001 \\
\hline Baluch & 1.00 & \\
\hline
\end{tabular}

Abbreviation: CI, Confidence Interval.

${ }^{a}$ Adjusted for: education, employment status, age, ethnicity.

conditions, respectively, compared with adults without chronic condition (22).

In a study conducted on the US population, the association between food insecurity and self-reported hypertension was examined among adults aged 35 or older in 12 states. Researchers found a positive relationship between food insecurity and hypertension after adjusting for selected characteristics. In the unadjusted model, food insecurity was associated with an increased likelihood of reporting hypertension. This association remained after adjusting for age, sex, race/ethnicity, education, marital status, current smoking status, percentage of federal poverty level, and health insurance coverage (29).

In Uganda, the prevalence of parasite was $4.1 \%$ among participants older than 5 years and 3.9\% among participants of all ages (30). In Australia, food insecurity was associated with poorer general health and increased use of health care (11).

When food insecurity exists, females are to report it
Table 4. Adjusted Odds Ratio for the Association Between Household Food Insecurity and Self-Reported History of Parasitic Diseases in Mothers of Households ( $\mathrm{n}=$ $2160)^{\mathrm{a}}$

\begin{tabular}{|c|c|c|}
\hline \multirow[t]{2}{*}{ Variable } & \multicolumn{2}{|c|}{ Food Insecurity } \\
\hline & Adjusted $^{\mathrm{a}}$ OR $(95 \% \mathrm{CI})$ & Pvalue \\
\hline \multicolumn{3}{|l|}{$\begin{array}{l}\text { Self-reported history of parasitic } \\
\text { diseases }\end{array}$} \\
\hline Yes & $3.86(1.07-13.93)$ & 0.039 \\
\hline No & 1.00 & \\
\hline \multicolumn{3}{|l|}{ Maternal education } \\
\hline Illiterate & $8.60(4.99-14.81)$ & $<0.001$ \\
\hline Elementary & $4.79(3.40-6.75)$ & $<0.001$ \\
\hline Secondary school & $2.87(2.08-3.96)$ & $<0.001$ \\
\hline High school and diploma & $2.34(1.78-3.08)$ & $<0.001$ \\
\hline University education & 1.00 & \\
\hline \multicolumn{3}{|l|}{ Mother's employment status } \\
\hline Housekeeper & $1.59(1.17-2.17)$ & 0.003 \\
\hline Employed & 1.00 & \\
\hline \multicolumn{3}{|l|}{ Maternal age, $y$} \\
\hline$\leq 26$ & $1.11(0.86-1.43)$ & 0.417 \\
\hline $27-35$ & $1.31(1.03-1.67)$ & 0.024 \\
\hline$\geq 35$ & 1.00 & \\
\hline \multicolumn{3}{|l|}{ Ethnicity } \\
\hline Fars (and other ethnic) & $0.65(0.51-0.83)$ & $<0.001$ \\
\hline Baluch & 1.00 & \\
\hline
\end{tabular}

Abbreviation: CI, Confidence Interval.

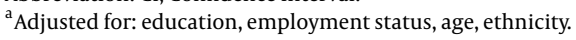

twice as males $(\mathrm{P}<0.01)$; and when females are food insecure and a member of a food-insecure household, they are more likely to report a disease (three times more than males) compared to males (17). Food insecurity increases the females' risk of health problems, and it also increases the likelihood of a wider range of health problems in adults, because food insecurity is considered as a barrier to health protective behaviors such as healthy eating. Perhaps, the association between chronic illness and food insecurity is bidirectional (22). On a household level, existence of food insecurity may propose a high grade of vulnerability to a wide range of outcomes such as overall poor health status (31).

Infectious diseases have compounding effects on health. An infection may weaken immune responses and lower nutritious intake, causing a higher morbidity from a variety of communicable and non-communicable diseases. Affected subpopulations have lower access to health knowledge, treatment and services, which increases the 
risk of coinfection with other infectious diseases of the poor (32).

Managing chronic diseases for which significant relations were observed requires further expenses for medications, transportation, special dietary requirements, and other services. Although food security and chronic conditions are separate matters, they are associated in many ways. In the context of the fight against chronic conditions, food security may be combined with consuming sufficient food and making healthy choices to help prevent, reduce, or eliminate chronic non-communicable diseases. Food security may be one of the ways to address the fight against some of diseases, but it is not the only way. Having adequate food and the right combination of nutrients may reduce the onset of diseases, but may not prevent the manifestation of diseases in susceptible individuals. Food security represents a controllable environmental agent that may possibly bring about some positive results in the fight against diseases (33).

Exposure to most of the main diseases, which in turn interact with nutrition, can be reduced by preventive procedures such as environmental sanitation or immunization. Environmental sanitation reduces the exposure to gastrointestinal pathogens, improves housing, and reduces thronging, which are important in controlling respiratory tract infections and malaria to some extent. Moreover, water quantity and quality and sanitation may have a considerable impact on nutritional status through reduced morbidity, savings in maternal time and energy, and improved food production. Considering the lack of specific nutritional interventions, general health procedures can have an important effect on nutritional status. The incidence of gastrointestinal infections and parasitic infestations can be significantly reduced by improved sanitation and safe drinking water (14). Infectious diseases affect nutritional status, either specifically or through unspecific mechanisms such as anorexia, tachypnea, and vomiting (34). Inadequate household food security is the underlying problem of malnutrition and disease. Access to health services and environmental health situations relate to essential drugs and immunizations, safe water, sanitation, and housing. Inadequate or delayed treatment also prolongs disease occurrence and severity (16). Diseases influence nutrition status through loss or malabsorption of nutrients, and food security through the need for funds and human resources to care for sick individuals (13).

\section{Conclusion}

The findings pointed out that more than half of the households suffer from food insecurity and that some mothers reported a positive history of infectious and parasitic diseases.

Individual nutrition outcomes feedback affects health because individual's vulnerability to infection or progression of disease can be altered by nutrition status (10). Maintenance of the nutritional state is highly important to strengthen the host and supply the elements for its defense and a better quality of life. In this sense, the patient's approach must always involve the 3 following areas simultaneously: early nutritional support, specific treatment of infection, and restoration of the immune system (13).

\section{Acknowledgments}

We would like to thank all mothers who participated in the study, and school of nutritional Sciences and dietetics, Tehran University of Medical Sciences, Tehran, Iran. Also, we thank all those who helped us in health care centers of Zahedan University of Medical Sciences and health promotion research center of Zahedan University of Medical Sciences. We also express our gratitude to all the coworkers who helped us in data collection.

\section{Footnotes}

Authors' Contribution: Data collection, article preparation, and data analysis waere done by the first author ( $\mathrm{Zi}$ nat Mortazavi) under the guidance of the second and third authors (Dr. Ahmad Reza Dorosty and Dr. Mohammad Reza Eshraghian), with a help of the fourth and fifth authors (Dr. Mohtasham Ghaffari and Dr. Alireza Ansari-Moghaddam).

Financial Disclosure: Authors have no financial interests related to the material in the manuscript.

Implication for Health Policy/Practice/Research/and Medical Education: This study was conducted to determine the household food insecurity and its association with self-reported infectious and parasitic diseases among household mothers in Southeast of Iran.

Funding/Support: This article was part of a Ph.D. thesis funded and supported by Tehran University of Medical Sciences, and the Research Deputy of Zahedan University of Medical Sciences, Iran.

\section{References}

1. Eisenmann JC, Gundersen C, Lohman BJ, Garasky S, Stewart SD. Is food insecurity related to overweight and obesity in children and adolescents? A summary of studies, 1995-2009. Obes Rev. 2011;12(5):e73-83. doi: 10.1111/j.1467-789X.2010.00820.x. [PubMed: 21382151]. 
2. Mello JA, Gans KM, Risica PM, Kirtania U, Strolla LO, Fournier L. How is food insecurity associated with dietary behaviors? An analysis with low-income, ethnically diverse participants in a nutrition intervention study. J Am Diet Assoc. 2010;110(12):1906-11. doi: 10.1016/j.jada.2010.09.011. [PubMed: 21111099].

3. Melchior M, Caspi A, Howard LM, Ambler AP, Bolton H, Mountain N, et al. Mental health context of food insecurity: a representative cohort of families with young children. Pediatrics. 2009;124(4):e564-72. doi: 10.1542/peds.2009-0583. [PubMed: 19786424].

4. Isanaka S, Mora-Plazas M, Lopez-Arana S, Baylin A, Villamor E. Food insecurity is highly prevalent and predicts underweight but not overweight in adults and school children from Bogota, Colombia. J Nutr. 2007;137(12):2747-55. [PubMed: 18029494].

5. Derose KP, Felician M, Han B, Palar K, Ramirez B, Farias H, et al. A prepost pilot study of peer nutritional counseling and food insecurity and nutritional outcomes among antiretroviral therapy patients in Honduras. BMC Nutr. 2015;1 doi: 10.1186/s40795-015-0017-7. [PubMed: 26702362].

6. Mohamadpour M, Sharif ZM, Keysami MA. Food insecurity, health and nutritional status among sample of palm-plantation households in Malaysia. J Health Popul Nutr. 2012;30(3):291-302. doi: 10.3329/jhpn.v30i3.12292. [PubMed: 23082631].

7. Semba RD, Campbell AA, Sun K, de Pee S, Akhter N, Moench-Pfanner $\mathrm{R}$, et al. Paternal smoking is associated with greater food insecurity among poor families in rural Indonesia. Asia Pac J Clin Nutr. 2011;20(4):618-23. [PubMed: 22094848].

8. Saad MB. Food security for the food insecure: New challenges and renewed commitments. CSD Women's Caucus Position Paper for CSD; 1999.

9. Council NR. Workforce needs in veterinary medicine. Washington, DC: National Academies Press; 2013. p. 310.

10. Hammond RA, Dube L. A systems science perspective and transdisciplinary models for food and nutrition security. Proc Natl Acad Sci U S A. 2012;109(31):12356-63. doi: 10.1073/pnas.0913003109. [PubMed: 22826247].

11. Lindberg R, Lawrence M, Gold L, Friel S, Pegram O. Food insecurity in Australia: Implications for general practitioners. Aust Fam Physician. 2015;44(11):859-62. [PubMed: 26590630].

12. Stuff JE, Casey PH, Szeto KL, Gossett JM, Robbins JM, Simpson PM, et al. Household food insecurity is associated with adult health status.J Nutr. 2004;134(9):2330-5. [PubMed: 15333724].

13. Pereira PCM. Interaction between infection, nutrition and immunity in tropical medicine. JVenom Anim Toxins Incl Trop Dis. 2003;9(2):16373. doi: 10.1590/s1678-91992003000200003.

14. Gillepsie SR, Manson J. Nutrition-relevant actions, ACC/SCN State-ofthe-art-Series. Nutrition policy discussion paper. 1991(10).

15. Parasites and foodborne illness. United States Department of Agriculture: Food Safety and Inspection Service; 2013.

16. Katona P, Katona-Apte J. The interaction between nutrition and infection. Clin Infect Dis. 2008;46(10):1582-8. doi: 10.1086/587658. [PubMed: 18419494].

17. Belachew T, Hadley C, Lindstrom D, Gebremariam A, Michael $\mathrm{KW}$, Getachew Y, et al. Gender differences in food insecurity and morbidity among adolescents in southwest Ethiopia. Pediatrics. 2011;127(2):e398-405. doi: 10.1542/peds.2010-0944. [PubMed: 21220395].

18. Behzadifar M, Behzadifar M, Abdi S, Malekzadeh R, Arab Salmani M, Ghoreishinia G, et al. Prevalence of Food Insecurity in Iran: A Systematic Review and Meta-analysis. Arch Iran Med. 2016;19(4):288-94.
[PubMed: 27041526].

19. Daneshi Maskooni M, Dorosty Motlagh A, Hosseini M, Zendehdel K, Kashani A, Safarpour M, et al. Food insecurity and some associated socioeconomic factors among upper gastrointestinal cancer patients. Int Res J Appl Basic Sci. 2013;4(2):482-6.

20. Sadrzadeh Yeganeh H, Eshraghian M, Daneshi M, Azizi S. Food insecurity status and some associated socioeconomic factors among newly diagnosed patients with type 2 diabetes in Shiraz, 2012 [In Persian]. Arak Med Univ J. 2013;16(1):98-106.

21. Charles J, Utermohle RSW, Fenaughty A. Food insecurity in Alaska. Chronicles. 2008;1(4).

22. Vozoris NT, Tarasuk VS. Household food insufficiency is associated with poorer health. J Nutr. 2003;133(1):120-6. [PubMed: 12514278].

23. Tarasuk V, Mitchell A, McLaren L, McIntyre L. Chronic physical and mental health conditions among adults may increase vulnerability to household food insecurity. J Nutr. 2013;143(11):1785-93. doi: 10.3945/jn.113.178483. [PubMed: 23986364].

24. Payab M, Dorosty AR, Eshraghian MR, Siassi F, Karimi T. Association of food insecurity with some of socioeconomic and nutritional factors in mothers with primary school child in Rey city. Iran J Nutr Sci Food Technol. 2012;7(1):75-84.

25. Ivers LC, Cullen KA. Food insecurity: special considerations for women. Am J Clin Nutr. 2011;94(6):1740S-4S. doi: 10.3945/ajcn.111.012617. [PubMed: 22089447].

26. Bickel G, Nord M, Price C, Hamilton W, Cook J. Guide to measuring household food security 2000. Available from: http://www.fnsusdagov/fsec/FILES/Guide\%20to\%20Measuring\% 20Household\%20Food\%20Security(3-23-00)pdf.

27. Ramesh T. The Prevalence of food insecurity and some associated factors among Shirazian households in 2009 [In Persian]. Tehran Shahid Beheshti University of Medical Sciences; 2009.

28. Rafiei M, Nord M, Sadeghizadeh A, Entezari MH. Assessing the internal validity of a household survey-based food security measure adapted for use in Iran. Nutr J. 2009;8:28. doi: 10.1186/1475-2891-8-28. [PubMed: 19558676]

29. Irving SM, Njai RS, Siegel PZ. Food Insecurity and Self-Reported Hypertension Among Hispanic, Black, and White Adults in 12 States, Behavioral Risk Factor Surveillance System, 2009. Prev Chronic Dis. 2014;11 doi: $10.5888 /$ pcd11.140190.

30. Lewnard JA, Berrang-Ford L, Lwasa S, Namanya DB, Patterson KA, Donnelly $B$, et al. Relative undernourishment and food insecurity associations with Plasmodium falciparum among Batwa pygmies in Uganda: evidence from a cross-sectional survey. Am J Trop Med Hyg. 2014;91(1):39-49. doi: 10.4269/ajtmh.13-0422. [PubMed: 24821844].

31. Chinnakali P, Upadhyay RP, Shokeen D, Singh K, Kaur M, Singh AK, et al. Prevalence of household-level food insecurity and its determinants in an urban resettlement colony in north India.J Health Popul Nutr. 2014;32(2):227-36. [PubMed: 25076660].

32. Salcito K, Singer BH, Weiss MG, Winkler MS, Krieger GR, Wielga M, et al. Multinational corporations and infectious disease: Embracing human rights management techniques. Infect Dis Poverty. 2014;3(1):39. doi: 10.1186/2049-9957-3-39. [PubMed: 25671119].

33. Pattron DD. Food security in the context of the fight against chronic diseases in the caribbean 2007. Available from: http://www. selfgrowth.com/print/544866.

34. Krawinkel MB. Interaction of nutrition and infections globally: an overview. Ann Nutr Metab. 2012;61 Suppl 1:39-45. doi: 10.1159/000345162. [PubMed: 23343946]. 